\title{
Introduction to open world learning
}

\section{Research, innovation and the challenges of high-quality education}

\section{Bart Rienties, Regine Hampel, Eileen Scanlon and Denise Whitelock}

\section{I.I Introduction}

The main objective of this book Open World Learning: Research, Innovation and the Challenges of High-Quality Education is to establish an informed theoretical and methodological basis for research and practical application of open world learning. With the global pandemic, nearly every person on this planet has been touched by the impact of COVID-19. In part, the unprecedented spread of COVID-19 has been due to the growth of technology and the interconnected nature of our societies across this planet. Thanks to global travel afforded by technology, a "small" infection in one part of the world rapidly infected millions of people across the globe in less than four months. At the same time, thanks to innovative technology millions of teachers and students were able to continue to learn online when many societies went into lockdown. Similarly, the unprecedented global race to find a vaccine would not have been able to complete successfully so quickly without technology and the combined forces of scientific research.

In these unprecedented and strange times, the power and limitations of technology have become even more visible to many. The rate of transition of learning in the 21st century has undergone both subtle and radical transformation as a result of COVID-19. Some of these changes were already starting to become visible in several parts of societies and educational systems in particular, such as moves towards blended and online education (Hampel, 2019). Other changes like working from home, attending online concerts, or creating Zoom discos have led to substantial organisational and personal changes in our daily lives, which we may not have seen for a decade without COVID-19.

Open world learning gives unprecedented access to information, knowledge, and education and provides support to learners across the globe. However, it is not the technologies themselves that represent the biggest change, but the opportunities for openness that flow from their thoughtful application, in the form of availability of and access to formal and informal learning (Ferguson, Jones, \& Scanlon, 2019; Littlejohn \& Margaryan, 2014). Without research to inform practice the changes in learning may exclude the very people who most stand to benefit from them. 
For example, those likely to complete free, online courses tend to be qualified to degree level already (Kizilcec, Saltarelli, Reich, \& Cohen, 2017; Rizvi, Rienties, Kizilcec, \& Rogaten, 2022). Ironically, the revolution in open world learning is in danger of increasing the digital divide by privileging those with the appropriate digital and learning skills to best take advantage of it (Iwaniec-Thompson, 2022; Nguyen, Rienties, \& Richardson, 2020). It is this issue that this edited book on open world learning will address.

The complex (Adams, Fitzgerald, \& Priestnall, 2013; Richardson, Mittelmeier, \& Rienties, 2020), contradictory (Bayne \& Land, 2013; Nguyen, Rienties, \& Richardson, 2020; Weller, 2020), and multidisciplinary (Ferguson et al., 2019; Hampel, 2014; Mittelmeier, Rienties, Gunter, \& Raghuram, 2020; Scanlon, 2014) nature of open world learning is fundamentally changing society and the foundations of education. This drives an urgent need to review the "enablers" and "disablers" of open world learning for inclusive approaches to learning across educational sectors, disciplines, and countries (Barber, 2021).

The world is becoming a more connected place with the emergence of immediate access systems, such as smartphones and tablets (Kukulska-Hulme et al., 2020; Srisontisuk, 2022), the omnipresence of social media like Facebook (Vogiatzis, Charitonos, Giaxoglou, \& Lewis, 2022), Twitter (Bruguera, Guitert, \& Romeu, 2019; Rehm, Cornelissen, Notten, Daly, \& Supovitz, 2020), WhatsApp (Madge et al., 2019; Vogiatzis et al., 2022), and new methods of working (Bond, ZawackiRichter, \& Nichols, 2019; Bruguera et al., 2019; Kukulska-Hulme et al., 2020; Lucena, Díaz, Reche, \& Rodríguez, 2019). This is accompanied by the advent of English as a lingua franca that is helping people to share information and communicate across the globe (Conde Gafaro, 2022; Hampel, 2014; Rets, Stickler, Coughlan, \& Astruc, 2022; Rienties, Lewis, O’Dowd, Rets, \& Rogaten, 2020; Vogiatzis et al., 2022).

Open world learning seeks to understand access to education, structures, and the presence of dialogue and support systems (Iniesto \& Hillaire, 2022; Mittelmeier et al., 2020; Weller, 2020). The challenge of open world learning is to foster inclusion and widen access to information, knowledge, and learning, rather than to allow people, organisations, and governments to increase divisions and build closed groups with privileged access to information and education. One key aspect of open world learning is openness: how approaches to learning can be designed to enable sharing and co-creation of knowledge (Iniesto, McAndrew, Minocha, \& Coughlan, 2022; Littlejohn et al., 2019; McAndrew \& Scanlon, 2013; Mohamud, Buckler, Pitt, \& Twining, 2022; Rizvi et al., 2022). However, these innovations are also changing how societies understand ownership of knowledge, information, expertise, and the process of learning.

Nonetheless, openness also has its disablers (e.g., restrictive quality assurance regimes, required integration across units, accreditation and costs), and the excluding power of "closed" systems (such as classrooms, universities, or corporate training programmes) may seem more persuasive in some situations (Ferguson et al., 2019; Korir, Mittelmeier, \& Rienties, 2020). Many open technologies are subject to - and still have in many cases - (over)inflated expectations as change agents (e.g., artificial intelligence-enabled learning, virtual world learning) whilst only providing different practices within the same educational parameters (e.g., 
in the context of a transmission-based approach to learning) (Bond et al., 2019; Neelen \& Kirschner, 2020; Rienties, Køhler Simonsen, \& Herodotou, 2020). Some of these "technical disruptions" actually contribute to maintaining restrictive educational norms and practices (Bayne \& Land, 2013; Nguyen, Rienties, \& Whitelock, 2022). This is, for example, the case with many MOOCs, which, despite their aspirations to fundamentally open up education, are not only based on a transmission-based paradigm but also used mainly by well-educated learners in Western countries (Kizilcec et al., 2017; Rizvi et al., 2022).

Similarly, there are ethical and privacy implications, for example, in learning analytics through increasing levels of monitoring, surveillance, and profiling (boyd \& Crawford, 2012; Korir et al., 2020; Korir, Slade, Holmes, \& Rienties, 2022), or public concerns whether open education will shift the balance of power of governments, schools, and educational institutions to a global, uncontrolled space. Finally, several groups of users (e.g., teachers, older people, people with particular accessibility needs) seem to struggle to embrace and integrate open technology, leading to resistance and anxieties towards new technologies (Bruguera et al., 2019; Iniesto et al., 2022; Iwaniec-Thompson, 2022; Nguyen, Rienties, \& Whitelock, 2020).

\section{I.2 Moving from practice to theory (and back to practice)}

At the moment, open world practice is leading theory (Gasevic, Dawson, Rogers, \& Gasevic, 2016; Herodotou et al., 2019; Neelen \& Kirschner, 2020; Weller, 2020), and research is needed to close this gap and allow experiences from particular contexts to inform generalised approaches with strong conceptual underpinnings. This ground-breaking and world leading book is a result of an award-winning (Open Education Consortium 2016) Leverhulme doctoral training programme that was structured to generate evidence, encourage theory construction, and lead to welldescribed new knowledge that informs practice across disciplines from $18 \mathrm{PhD}$ students at The Open University, UK (OU). The OU has been on the forefront of continuous innovation in open and distance education for over 50 years (Barber, 2021; Ferguson et al., 2019; Lucena et al., 2019; Weller, 2020).

The main question of this book is as follows: How can open world learning supported by technology help and/or hinder tackling the global challenges that open and high-quality education faces? First, this book provides an integrated and cohesive perspective of the affordances and limitations of open world learning. We strive to build a bridge that connects a range of research communities (e.g., artificial intelligence, computing, educational psychology, HCI, language education, learning analytics, learning sciences, linguistics, Open Educational Resource) that draw theoretically, conceptually, and analytically from each other, but have not always engaged in discussions to learn from each other's perspectives. Second, this book features a wide range of open world learning topics, ranging from theoretical and methodological discussions to empirical demonstrations of how open world learning may be actually implemented, evaluated, and used to inform theory and practice. Furthermore, this book will provide indepth analyses of the potential benefits and limitations of open world learning by 
bringing together insights from 387,134 learners, practitioners, and educators working and learning in 136 unique learning contexts (e.g., online courses, MOOCs, Internet kiosks).

\section{I.3 Rationale and structure of this book}

This book will provide state-of-the-art contemporary research insights of key systems, applications, and processes in open world learning. There is a need to raise awareness of academics, researchers, professionals, and policymakers regarding the affordances and limitations of technologies and approaches related to open world learning, and how this influences daily practice around us. This book provides new and substantial findings from 41 leading and promising early-career researchers and academic supervisors from 13 institutions in open world learning (for a full list, see list of contributors). Furthermore, the chapters focus on a range of countries, including Greece, Italy, the Netherlands, Uganda, and the UK, while five chapters obtained data and perspectives from across the globe.

Although we have developed this book as a collaborative project with a particular and hopefully logical structure, each chapter in itself can be read as an individual piece of academic work. Through clear referencing throughout the book, interested readers can delve into specific sections or chapters or read the book in a non-linear manner. Nonetheless, here is a brief overview of the book.

After a general introduction and overview of the affordances and limitations of open world learning by using both a macro-meso-micro and 4P lens (i.e., people, places, practices, properties) in Chapter 2 (Rienties, 2022), in Part 1 Learners and the power of language in an open world, we provide six chapters on how learners across the globe can use the power of English language to communicate together in an open world. The five chapters in Part 2 Innovative technologies in an open world provide insight into innovative technologies that have been implemented and evaluated in an open world, including internet kiosks, MOOCs, online games, and sentiment mining. Finally, in Part 3 Educators and inclusive practice in an open world, we specifically look at the role of educators in supporting inclusive practices in an open world. In the remainder of this chapter, an overview of each of the 19 chapters provides you, the reader, the opportunity to identify which Part(s) and/or Chapter(s) may be most relevant for you.

\subsection{Part I Learners and the power of language in an open world}

A common language is essential for learning in an open world and for learners to be able to communicate with each other. Part 1 comprises six chapters on how learners across the globe can use the power of (English) language to communicate together in an open world. Three chapters focus on adult learners (Conde Gafaro, 2022; Rets et al., 2022;Vogiatzis et al., 2022), two focus on MOOC learners (Chua, 2022; Rizvi et al., 2022), and one on children (Anastasiou, 2022). Furthermore, a mix of methodological approaches is used to unpack the complexities of language 
learning in an open world, including qualitative (Anastasiou, 2022) and multiple/ mixed-methods (Chua, 2022; Conde Gafaro, 2022; Rets et al., 2022; Rizvi et al., 2022; Vogiatzis et al., 2022). Finally, a mix of digital and online tools in an open world learning context are used in these chapters, including Futurelearn (Chua, 2022; Conde Gafaro, 2022; Rizvi et al., 2022), Open Educational Resources (Rets et al., 2022), WhatsApp (Vogiatzis et al., 2022), and YouTube (Anastasiou, 2022).

In Chapter 3, Popi Anastasiou (2022) provides a rich and detailed study of 31 Greek primary-school children who in an experimental design worked together in small groups on developing digital stories in science in either a story sequencing activity or story verbalisation activity. The findings indicate that story sequencing allowed children to position themselves as story makers, who employed decision-making strategies to determine the content of the story according to their preferred order of presentation. In contrast, in the story verbalisation groups, children were acting as story re-tellers, who mainly verbalised pre-defined content. Chapter 3 highlights how children from an early age onwards can creatively use a range of open world learning tools to tell their own stories and make meaning in their own language.

In Chapter 4, Dimitrios Vogiatzis et al. (2022) explore how WhatsApp can be effectively used for language learning by adults in a German context. Using a case study design with online observations and semi-structured interviews, the authors explore group interactions between eight learners over 22 weeks. The findings indicate adult learners' reactive participation, and mostly limited interaction, emphasising that the mere use of WhatsApp cannot necessarily guarantee language interaction among participants. This is an important finding as just having a common open world learning tool does not necessarily imply that all learners will be able to successfully interact and learn with these kinds of tools, and points to the crucial area of learning design explored later in this book.

In Chapter 5, Barbara Conde Gafaro (2022) examines the self-regulated learning behaviours of 19 language learners who engage with MOOCs as part of a blend with their language learning courses. Using a mix of thematic analysis and measurements of self-regulated learning, the findings indicate that learners not only set short-term goals but also set multiple reflexive learning goals as part of their MOOC experience. Supporting learners in the process of goal setting may contribute to increasing their engagement with blended language courses.

In Chapter 6, Shi Min Chua (2022) uses an innovative corpus linguistic approach to understand how learners communicate in large open spaces like MOOCs. In a big data exploration of online discussions containing 11 million word contributions from 228,665 learners in 12 Futurelearn MOOCs, the findings indicate how learners use particular communicative strategies can significantly influence whether (or not) other learners are going to reply to a message, and how conversations can be made meaningful when they reply to each other, without causing hard feeling but making it an open discussion. Chapter 6 highlights again the importance of language use and suggests several useful writing tips for learners who would like to open a conversation with others in online discussion.

In Chapter 7, Irina Rets et al. (2022) explore how Open Educational Resources (OERs) could be made more accessible for non-native English speakers using a 
mixed method of eye-tracking with simulated recall interviews with nine participants. The findings from in-depth analyses with nine participants indicate that decreasing the complexity level of OERs by text simplification led to a reduction in cognitive load and an increase in higher-level processing. Given the global reach of online learning tools and educational resources, this chapter highlights that teachers need to carefully balance their language usage to make it accessible for both native and non-native language speakers.

Finally, in Chapter 8 Saman Rizvi et al. (2022) provide two studies to explore whether or not MOOCs are culturally inclusive. The first study uses a quantitative approach to investigate the extent to which engagement by 49,582 learners in ten Futurelearn MOOCs varied between geo-cultural contexts, while the second follow-up study examines the link between learners' geo-cultural background and their perspectives about how different elements of learning design contribute towards their learning. The findings suggest that learners from different geocultural backgrounds substantially differed in their engagements in MOOC activities (e.g., articles discussions, videos), while the qualitative findings highlighted large perceived cultural differences in the value of certain MOOC activities, which in part were influenced by participants English language abilities. This further highlights the need for learners and teachers to recognise that while open world learning approaches are theoretically open to all, in practice they are not necessarily inclusive for anyone and everyone.

\section{I.3.2 Part 2 Innovative technologies in an open world}

Part 2 contains five chapters focusing on innovative technologies that have been implemented and evaluated in an open world context. Two chapters focus on students (Hillaire, Rienties, Fenton-O'Creevy, Zdrahal, \& Tempelaar, 2022; Korir et al., 2022), two use a multi-stakeholder perspective (Iniesto et al., 2022; Mohamud et al., 2022), and one focuses on gamers (Hall, Herodotou, \& Iacovides, 2022), Furthermore, a mix of methodological approaches is used to unpack the complexities of implementing innovative technologies in an open world, including qualitative (Mohamud et al., 2022), quantitative (Hall et al., 2022) and multiple/ mixed-methods (Hillaire et al., 2022; Iniesto et al., 2022; Korir et al., 2022). Finally, like in Part 1 a mix of open world learning tools are used in these chapters, including digital games (Hall et al., 2022), Futurelearn (Iniesto et al., 2022), solar-powered internet kiosks (Mohamud et al., 2022), Prolific (Korir et al., 2022), and a student sourced sentiment analysis classifier (Hillaire et al., 2022).

In Chapter 9, Francisco Iniesto et al. (2022) explore the accessibility in MOOCs via interviews with 40 MOOC providers designers and 34,026 learners using a mixed method of survey data and an accessibility audit. The findings indicate that while substantial progress has been made over the years to improve accessibility in MOOCs, substantial barriers remain, and at times rather than making designs inclusive some providers have restricted access. Chapter 9 concludes with a call for inclusive design by adding in a consideration of specific learner groups so that they are included, potentially through alternative design solutions rather than one design solution. 
In Chapter 10, Khadija Mohamud et al. (2022) illustrate the impact of solarpowered internet kiosks on 50 users in two urban low-income communities in Uganda. The findings highlight how users utilised these centres to empower themselves beyond the use of technology. Specifically, this is related to supporting young people and teachers with instructional resources to bridge gaps in education and providing low-income communities with a social space where they nurtured meaningful relationships cultivating their sense of belonging. Furthermore, Chapter 10 illustrates how the technology allowed others to learn and also raised some safety concerns.

In Chapter 11, Maina Korir et al. (2022) explore how the crowdsourcing platform Prolific could be used to elicit students' data use preferences for learning analytics. In an experimental design, 447 students from different higher and further education institutions in the UK were presented with privacy risks and/or benefits interventions to examine whether and how these would influence their data use preferences. The findings indicate that these interventions did not substantially alter participants' privacy notions and support of institutional use of student data. Participants' responses indicated that they made trade-offs to arrive at what was an acceptable use of student data for them.

In Chapter 12, Johanna Hall et al. (2022) explore how creativity in digital games plays a role in openness to experience, emotional wellbeing, and meaningful learning. By developing a Creativity in Gaming Scale (CGS) instrument based upon the input from 251 gamers, the authors provide a powerful tool for teachers and learners to explore whether their digital games encourage creativity, including problemsolving and appropriation.

Finally, in Chapter 13, Garron Hillaire et al. (2022) explore how student voices and inputs can be used to develop a student sourced sentiment analysis classifier. While most off-the-shelf sentiment analysis tools are developed outside education and educational context, by analysing online contributions by 1,251 students at one university in the Netherlands to an online collaborative experiment and afterwards asking them to code their own and others emotions, an inclusive classifier is developed. The findings indicate that this classifier is able to accurately identify emotions in online chat.

\subsubsection{Part 3 Educators and inclusive practice in an open world}

Finally, in Part 3, we look specifically at the role of educators, teachers, and professionals in supporting inclusive practices in an open world. Two chapters specifically focus on how teachers make learning design decisions (Iniesto \& Hillaire, 2022; Nguyen et al., 2022), one focuses on teachers in early years contexts (Srisontisuk, 2022), one on finance professionals (Chaudhari, Littlejohn, \& Cross, 2022), and one on older academics (Iwaniec-Thompson, 2022). Furthermore, again a mix of methodological approaches is used to unpack the complexities of how educators and professionals make sense of an open world, including qualitative (Chaudhari et al., 2022; Iniesto \& Hillaire, 2022; Iwaniec-Thompson, 2022; Srisontisuk, 2022) and multiple/mixed-methods (Nguyen et al., 2022). Finally, 
like in Part 1 and Part 2, a range of open world learning tools is used in these chapters, including FutureLearn (Iniesto \& Hillaire, 2022), learning analytics (Nguyen et al., 2022), and Ipads (Srisontisuk, 2022).

In Chapter 14, Quan Nguyen et al. (2022) explore how the use of data on how teachers design their courses can inform our understanding of students' engagement with online learning activities. By mapping both 70,000 students and 39 teachers' data, this data-driven approach provides teachers with the opportunity to reflect on their course design through visualisations of weekly learning activities which highlights the workload and the variety of teaching approaches.

In Chapter 15, Francisco Iniesto and Garron Hillaire (2022) apply a Universal Design for Learning (UDL) approach to map how effective a range of MOOCs from different providers are in terms of accessibility. When producing educational resources, all stakeholders should be considered in their design and evaluation processes including educators and learners. The iterative and refinement processes shown in Chapter 15 indicate that UDL, as a proactive design framework, can be used for evaluation, and facilitate and help with internalisation of its principles.

In Chapter 16, Pinsuda Srisontisuk (2022) explores the rich and diverse perspectives of nine UK teachers on smartphone and tablets technologies in two classrooms. The findings indicate most children can use tablets with minimal instruction, although there remains a fear amongst teachers around the technology leading to an increase in learners being passive and not engaging in other social and physical activity. Nonetheless, the teachers also reported that one of the most beneficial features was the connectivity to the world wide web; instant access to knowledge and images was a feature they felt has enhanced the learning experience for the children.

In Chapter 17,Vasudha Chaudhari et al. (2022) explore how nine professionals in the finance sector make sense of uncertainty. The findings suggest that although uncertainty is experienced by all professionals irrespective of their level of expertise, there are distinct differences in the way uncertainty is perceived by experts and practitioners. Chapter 17 presents the similarities and differences in perception of uncertainty and discusses the implications of these findings for practice.

Finally, in Chapter 18, Gosia Iwaniec-Thompson (2022) explores how eleven older academics are conceptualising their identity development and use of technology in particular. The manifestation of subjectivities occurs when academics exert influence and take stances affecting their practice and impact on the construal of their professional identity. For some, open world tools like ResearchGate were helpful for developing their identities, while other tools led to uncertainty among the academics of how to integrate these into their teaching practice.

\section{I.4 Discussion}

In this book, we will bring together some diverse perspectives and narratives around open world learning from 387,134 learners and teachers working in 136 learning contexts. As highlighted in the final Chapter 19 (Rienties, Hampel, Scanlon, \& Whitelock, 2022) and throughout this book, while open world learning approaches, methods, and tools provide many affordances for learners, teachers, and 
professionals, not everyone is able to necessarily benefit from these just because these are "open". In this book and in Chapter 19, we suggest a range of practical steps that you as reader can do to ensure that the power of open world learning is as inclusive as possible.

\section{References}

Adams, A., Fitzgerald, E., \& Priestnall, G. (2013). Of catwalk technologies and boundary creatures. ACM Transactions on Computer-Human Interaction, 20(3), 1-34. doi: 10.1145/ 2491500.2491503

Anastasiou, P. (2022). Digital stories in science: the role of story sequencing. In B. Rienties, R. Hampel, E. Scanlon, \& D. Whitelock (Eds.), Open World Learning: Research, Innovation and the Challenges of High-Quality Education (pp. 29-43). London: Routledge.

Barber, M. (2021). Gravity assist: Propelling higher education towards a brighter future. London: Office for Students.

Bayne, S., \& Land, R. (2013). Education in cyberspace. London: Routledge.

Bond, M., Zawacki-Richter, O., \& Nichols, M. (2019). Revisiting five decades of educational technology research: A content and authorship analysis of the British Journal of Educational Technology. British Journal of Educational Technology, 50(1), 12-63. doi: 10.1111/bjet. 12730

boyd, D., \& Crawford, K. (2012). Critical questions for big data: Provocations for a cultural, technological, and scholarly phenomenon. Information, Communication \& Society, 15(5), 662-679. doi: 10.1080/1369118X.2012.678878green

Bruguera, C., Guitert, M., \& Romeu, T. (2019). Social media and professional development: a systematic review. Research in Learning Technology, 27. doi: 10.25304/rlt.v27.2286

Chaudhari, V., Littlejohn, A., \& Cross, S. (2022). Antecedents and consequences of uncertainties perceived by finance professionals. In B. Rienties, R. Hampel, E. Scanlon, \& D. Whitelock (Eds.), Open World Learning: Research, Innovation and the Challenges of HighQuality Education (pp. 237-249). London: Routledge.

Chua, S. M. (2022). Discourse practices in MOOC discussions: A corpus linguistic approach. In B. Rienties, R. Hampel, E. Scanlon, \& D. Whitelock (Eds.), Open World Learning: Research, Innovation and the Challenges of High-Quality Education (pp. 76-88). London: Routledge.

Conde Gafaro, B. (2022). First steps towards self-regulated learning: Setting goals in MOOCs. In B. Rienties, R. Hampel, E. Scanlon, \& D. Whitelock (Eds.), Open World Learning: Research, Innovation and the Challenges of High-Quality Education (pp. 63-75). London: Routledge.

Ferguson, R., Jones, A., \& Scanlon, E. (2019). Educational visions: The lessons from 40 years of innovation. London: Ubiquity Press.

Gasevic, D., Dawson, S., Rogers, T., \& Gasevic, D. (2016). Learning analytics should not promote one size fits all: The effects of instructional conditions in predicating learning success. Internet and Higher Education, 28(January 2016), 68-84. doi: 10.1016/j.iheduc.2015.10.002

Hall, J., Herodotou, C., \& Iacovides, I. (2022). Measuring player creativity in digital entertainment games using the Creativity in Gaming Scale. In B. Rienties, R. Hampel, E. Scanlon, \& D. Whitelock (Eds.), Measuring Player Creativity in Digital Entertainment Games using the Creativity in Gaming Scale (pp. 157-170). London: Routledge.

Hampel, R. (2014). Enhancing interaction and communication in distance language learning by using new technologies. Distance Education in China, 5, 11-19. 
Hampel, R. (2019). Disruptive technologies and the language classroom. Cham: Springer.

Herodotou, C., Sharples, M., Gaved, M., Kukulska-Hulme, A., Rienties, B., Scanlon, E., \& Whitelock, D. (2019). Innovative pedagogies of the future: An evidence-based selection. Frontiers in Education, 4(113). doi: 10.3389/feduc.2019.00113

Hillaire, G., Rienties, B., Fenton-O'Creevy, M., Zdrahal, Z., \& Tempelaar, D. T. (2022). Incorporating student opinion into opinion mining: A student sourced sentiment analysis classifier. In B. Rienties, R. Hampel, E. Scanlon, \& D. Whitelock (Eds.), Open World Learning: Research, Innovation and the Challenges of High-Quality Education (pp. 171-186). London: Routledge.

Iniesto, F, \& Hillaire, G. (2022). UDL and its implications in MOOC accessibility evaluation. In B. Rienties, R. Hampel, E. Scanlon, \& D. Whitelock (Eds.), Open World Learning: Research, Innovation and the Challenges of High-Quality Education (pp. 208-224). London: Routledge.

Iniesto, F., McAndrew, P., Minocha, S., \& Coughlan, T. (2022). Accessibility in MOOCs: the stakeholders' perspectives. In B. Rienties, R. Hampel, E. Scanlon, \& D. Whitelock (Eds.), Open World Learning: Research, Innovation and the Challenges of High-Quality Education (pp. 119-130). London: Routledge.

Iwaniec-Thompson, G. (2022). The identity trajectories of older academics: workplace affordances and individual subjectivities. In B. Rienties, R. Hampel, E. Scanlon, \& D. Whitelock (Eds.), Open World Learning: Research, Innovation and the Challenges of HighQuality Education (pp. 250-263). London: Routledge.

Kizilcec, R., Saltarelli, A. J., Reich, J., \& Cohen, G. L. (2017). Closing global achievement gaps in MOOCs. Science, 355(6322), 251-252. doi: 10.1126/science.aag2063

Korir, M., Mittelmeier, J., \& Rienties, B. (2020). Is mixed methods social network analysis ethical? In D. Froehlich, M. Rehm, \& B. Rienties (Eds.), Mixed Methods Approaches to Social Network Analysis (pp. 206-218). London: Routledge.

Korir, M., Slade, S., Holmes, W., \& Rienties, B. (2022). Eliciting students' preferences for the use of their data for learning analytics: A crowdsourcing approach. In B. Rienties, R. Hampel, E. Scanlon, \& D. Whitelock (Eds.), Open World Learning: Research, Innovation and the Challenges of High-Quality Education (pp. 144-156). London: Routledge.

Kukulska-Hulme, A., Beirne, E., Conole, G., Costello, E., Coughlan, T., Ferguson, R., ... Whitelock, D. (2020). Innovating Pedagogy 2020 Open University Innovation Report 8. Milton Keynes: The Open University.

Littlejohn, A., Hood, N., Rehm, M., McGill, L., Rienties, B., \& Highton, M. (2019). Learning to become an online editor: the editathon as a learning environment. Interactive Learning Environments. doi: 10.1080/10494820.2019.1625557

Littlejohn, A., \& Margaryan, A. (2014). Technology-enhanced Professional Learning: Processes, Practices, and Tools. New York: Routledge.

Lucena, F. J. H., Díaz, I. A., Reche, M. P. C., \& Rodríguez, J. M. R. (2019). A tour of Open Universities through literature. The International Review of Research in Open and Distributed Learning, 20(4). doi: 10.19173/irrodl.v20i3.4079

Madge, C., Breines, M., Beatrice Dalu, M. T., Gunter, A., Mittelmeier, J., Prinsloo, P., \& Raghuram, P. (2019). WhatsApp use among African international distance education (IDE) students: transferring, translating and transforming educational experiences. Learning, Media and Technology, 44(3), 267-282.

McAndrew, P., \& Scanlon, E. (2013). Open learning at a distance: Lessons for struggling MOOCs. Science, 342(6165), 1450-1451. doi: 10.1126/science.1239686 
Mittelmeier, J., Rienties, B., Gunter, A., \& Raghuram, P. (2020). Conceptualizing Internationalization at a Distance: A "third category" of university internationalization. Journal of Studies in International Education, 1028315320906176. doi: 10.1177/ 1028315320906176

Mohamud, K., Buckler, A., Pitt, B., \& Twining, P. (2022). Internet kiosks in Uganda: A window of opportunities? In B. Rienties, R. Hampel, E. Scanlon, \& D. Whitelock (Eds.), Open World Learning: Research, Innovation and the Challenges of High-Quality Education (pp. 131143). London: Routledge.

Neelen, M., \& Kirschner, P. A. (2020). Evidence-Informed Learning Design: Creating Training to Improve Performance. London: Kogan Page Publishers.

Nguyen, Q., Rienties, B., \& Richardson, J. T. E. (2020). Learning analytics to uncover inequality in behavioural engagement and academic attainment in a distance learning setting. Assessment and Evaluation in Higher Education, 45(4), 594-606. doi: 10.1080/ 02602938.2019.1679088

Nguyen, Q., Rienties, B., \& Whitelock, D. (2020). A mixed-method study of how instructors design for learning in online and distance education. Journal of Learning Analytics, 7(3), 64-78. doi: 10.18608/jla.2020.73.6

Nguyen, Q., Rienties, B., \& Whitelock, D. (2022). Informing learning design in online education using learning analytics of student engagement. In B. Rienties, R. Hampel, E. Scanlon, \& D. Whitelock (Eds.), Open World Learning: Research, Innovation and the Challenges of High-Quality Education (pp. 189-207). London: Routledge.

Open Education Consortium (2016). 2016 OE Award Winners. Accessed 04 October 2021. https://www.oeconsortium.org/projects/open-education-awards-for-excellence/ 2016-winners-of-oe-awards/2016-oe-award-winners-projects/

Rehm, M., Cornelissen, F., Notten, A., Daly, A., \& Supovitz, J. (2020). Power to the people?! Twitter discussions on (educational) policy processes. In D. Froehlich, M. Rehm, \& B. Rienties (Eds.), Mixed Methods Approaches to Social Network Analysis (pp. 231-244). London: Routledge.

Rets, I., Stickler, U., Coughlan, T., \& Astruc, L. (2022). Simplification of Open Educational Resources in English: Exploring its effect on text processing of non-native English speakers. In B. Rienties, R. Hampel, E. Scanlon, \& D. Whitelock (Eds.), Open World Learning: Research, Innovation and the Challenges of High-Quality Education (pp. 89-102). London: Routledge.

Richardson, J.T. E., Mittelmeier, J., \& Rienties, B. (2020). The role of gender, social class and ethnicity in participation and academic attainment in UK higher education: an update. Oxford Review of Education, 46(3), 346-362. doi: 10.1080/03054985.2019.1702012

Rienties, B. (2022). Powers and limitations of open world learning: Experiences from the field of education. In B. Rienties, R. Hampel, E. Scanlon, \& D. Whitelock (Eds.), Open World Learning: Research, Innovation and the Challenges of High-Quality Education (pp. 13-26). London: Routledge.

Rienties, B., Hampel, R., Scanlon, E., \& Whitelock, D. (2022). Reflecting on the main findings and practical applications. In B. Rienties, R. Hampel, E. Scanlon, \& D. Whitelock (Eds.), Open World Learning: Research, Innovation and the Challenges of High-Quality Education (pp. 264-272). London: Routledge.

Rienties, B., Køhler Simonsen, H., \& Herodotou, C. (2020). Defining the boundaries between Artificial Intelligence in Education, Computer-Supported Collaborative Learning, Educational Data Mining, and Learning Analytics: A need for coherence. Frontiers in Education, 5(128). doi: 10.3389/feduc.2020.00128 


\section{I2 Bart Rienties et al.}

Rienties, B., Lewis, T., O’Dowd, R., Rets, I., \& Rogaten, J. (2020). The impact of Virtual Exchange on TPACK and foreign language competence: reviewing a large-scale implementation across 23 Virtual Exchanges. Computer Assisted Language Learning. doi: 10.1080/09588221.2020.1737546.

Rizvi, S., Rienties, B., Kizilcec, R., \& Rogaten, J. (2022). Culturally adaptive learning design: A mixed-methods study of cross-cultural learning design preferences in MOOCs. In B. Rienties, R. Hampel, E. Scanlon, \& D. Whitelock (Eds.), Open World Learning: Research, Innovation and the Challenges of High-Quality Education (pp. 103-116). London: Routledge.

Scanlon, E. (2014). Scholarship in the digital age: Open educational resources, publication and public engagement. British Journal of Educational Technology, 45(1), 12-23. doi:10.1111/ bjet. 12010

Srisontisuk, P. (2022). Practitioner's perspective on young children's use of mobile technology. In B. Rienties, R. Hampel, E. Scanlon, \& D. Whitelock (Eds.), Open World Learning: Research, Innovation and the Challenges of High-Quality Education (pp. 225-236). London: Routledge.

Vogiatzis, D., Charitonos, K., Giaxoglou, K., \& Lewis, T. (2022). Can WhatsApp facilitate interaction? A case study of adult language learning. In B. Rienties, R. Hampel, E. Scanlon, \& D. Whitelock (Eds.), Open World Learning: Research, Innovation and the Challenges of HighQuality Education (pp. 44-62). London: Routledge.

Weller, M. (2020). Open and free access to education for all. In D. Burgos (Ed.), Radical Solutions and Open Science (pp. 1-15). Singapore: Springer. 